\title{
DE SURINAAMSE PERS GEDURENDE HET ENGELSE TUSSENBESTUUR
}

DOOR

\section{Ph. A. Samson (Suriname)}

Het tijdperk van het Engelse tussenbestuur is voor de geschiedschrijvers van Suriname steeds een dankbaar onderwerp geweest. WolBERS (1861) heeft dit tijdperk uitgebreid behandeld. EinaAR (1934) heeft er zijn proefschrift aan gewijd, en in de bespreking hiervan heeft MENkMAN (1936), in de 17e jaargang van de W.I.Gids, er verschillende interessante gegevens over gepubliceerd. Oudschans Dentz (1941) schreef in de 23e jaargang van de W.I. Gids over de, in die tijd levende boekhoudergeneraal JAN VAN DER TUUK ${ }^{1}$ ).

De vraag laat zich stellen, of er, ná de genoemde bijdragen, van deze belangrijke periode uit de geschiedenis van Suriname nog wel veel te vertellen is. De bestudering van de Surinaamse kranten uit die tijd heeft mij die vraag bevestigend doen beantwoorden.

Uit de Landsboekerij kon ik de beschikking krijgen over de nieuwsbladen welke in die tijd verschenen, met uitzondering van de jaargangen 1805, 1807 en 1810. $\mathrm{Zij}$ geven enigszins een beeld van het leven in die tijd en van de omstandigheden waaronder men toen leefde, en doen ons bijzonderheden kennen omtrent personen, die toen een rol in de Surinaamse samenleving hebben gespeeld.

In deze bijdrage wil ik trachten enkele gegevens uit deze bronnen te publiceren. Achtereenvolgens zal worden behandeld: 1. Pers; 2. verovering en teruggave van Suriname; 3 . binnenlands nieuws; 4. buitenlandse berichtgeving; 5 . advertenties.

1) Over Curaçao onder het Engels bestuur (1807-1816) schreef DE GaAY FORTMAN in de W. I. Gids, jrg. 27. 
DE SURINAAMSE PERS GEDURENDE HET ENGELSE TUSSENBEST. 81

P ers.

De inhoud van de kranten uit de Engelse tijd bestaat hoofdzakelijk uit advertenties en buitenlandse berichten, overgenomen uit kranten van Demerary, Barbados, U.S.A. en af en toe uit Europese nieuwsbladen.

De Surinaamsche Courant van 1804 is voorzien van de spreuk „Relata Refero” (ik vertel wat mij verteld is) en daaronder: „,Te weeten hoe het Elders gaat, Voedt den geest, en Stut den Staat". Van 18 April 1804 af is de spreuk vervangen door: „,Der Waarheid toegedaan en van Partijzucht Vrij”.

Als drukkers van deze kranten vinden wij vermeld: J. VoEgEN, Van Engelen, L. E. H. Heyman, J. C. Karseboom, P. J. Rives, A. T. Bordas en Company, Rens, Fuchs, H. J. Serres en I. BRINK.

Gedurende het Engelse tussenbestuur werden de bladen in twee talen uitgegeven. Het laatste nummer van de Gepriviligeerde Surinaamsche Courant in beide talen, verscheen op Maandag 26 Febr. 1916.

Alle bladen verschenen in vier bladzijden, voor driekwart gevuld met officiële aankondigingen en advertenties.

Invoer van geschriften uit het buitenland mocht niet plaats hebben dan met goedkeuring van de gouverneur. Bij publicatie van 21 April 1804 had gouverneur P. BERRANGER ter kennis van de bevolking gebracht ,,dat van nu voortaan geene Werken of Geschriften, in de wijdste zin, en dus zelf geene Jaarboeken, Maand, Week of Dagschriften elders door den Druk algemeen gemaakt, in deeze Colonie, door wie hij zij, zullen mogen worden ingebragt zonder Onze approbatie". Op overtreding van dit bevel stond een geldboete van $f 500$, waarvan $1 / 3$ ten behoeve van de officie-fiscaal, $1 / 3$ ten behoeve van het militair hospitaal en $1 / 3$ voor de aanbrenger.

Verovering en teruggave van Suriname.

De geschiedschrijvers vermelden als datum van de overgave 28 Apr. 1804. In de Sur. Crt van 2 Mei 1804 komt een bericht voor, dat aantoont, dat van die overgave op dat tijdstip officieel nog niets bekend was. Dit bericht luidt: ,,Was er ooit een tijdstip sedert het oprijzen van dit Wingewest, uit de moerassen van Amerika, dat den geest van de daarin belanghebbenden, gaande maakte, zo is het gewis het tegenwoordige. Nog weeten wij niet, of de Nationale heldhaftigheid der Bataven dan of de stoutmoedigheid der strijders van Albion dit plekje Lands, door den 
onmeetbare Oceaan van het Moederland afgescheiden, behouden of vermeesteren zal. In beide gevallen, dog van welke evenwel maar een kan plaats hebben, zal de gematigde, bescheiden en zich na de omstandigheden des tijds verstandig, voegende Conduite aller wel gezinde Colonisten oneindig veel bijdragen tot het Coloniale Welzijn".

In het nummer van 5 Mei lezen wij, dat onder het afdrukken van het blad het politieke raadsel, waarover men zich sedert 10 dagen de hoofden gebroken heeft, zijn oplossing allengs begint te naderen en de inhoud van de publicatie op heden niet langer aan het lot van de Colonie doet twijfelen. Hierop volgt: „Het middelpunt der verdeediging aan den Overwinnaar afgestaan zijnde, vervalt alle verdere tegenkanting van zelve, en ieder vriend der menschheid alhier, en zijnder Mede Colonisten zal het bestier der voorzienigheid zegenen, dat geen Burger Bloed vergooten is, noch dat andere rampen welke beleegeringen gewoonlijk vergezellen, over onze schedels uitgebarsten zijn".

„Geve de Hemel, dat de finaale uitkomst der zaken volkomen mooge beantwoorden aan de verwagting en wensch aller weldenkende Inwooners van dit Wingewest, die hoe zeer zonder vergieting van bloed, evenwel al veele jaren herwaards, rijkelijk in de onheilen des Oorlogs hebben deelen moeten" ${ }^{1}$ ).

De proclamatie van Sir Charles GreEN, waarin hij aan de ingezetenen kennis geeft, dat Suriname onder de macht van de Koning van Groot Brittannië is gekomen en hij alle ,inwoners derzelve" uitnodigt de eed van trouw aan Zijne Majesteit te Gouvernementshuize te komen afleggen, is gedagtekend 19 Mei en opgenomen in de Sur. Crt van 30 Mei 1804.

In no. 39 van dit blad, dat op 20 Mei 1804 uitkwam, verscheen een aankondiging van de drukker, luidende: „By order of Goverment this Newspaper will be Printed in futur in the Dutch and English language". Van 30 Mei af verscheen het dan ook in een Nederlandse èn een Engelse tekst.

Men zou kunnen vragen hoe het mogelijk is, dat, terwijl de Engelsen op 28 April bezit van Suriname namen, dit in Paramaribo eerst op 5 Mei bekend werd. Het antwoord hierop is, dat de Engelse vloot, na eerst Braamspunt en Leyden te hebben veroverd, het fort Nieuw-Amsterdam aanviel, dat door kommandeur BATENBURG zonder verdediging en zonder Gouver-

1) Wolbers (1861) neemt deze artikelen over, doch vermeldt als datum van het laatste bericht 3 in plaats van 5 Mei. 
neur BERRANGER er in te kennen, werd overgegeven, en het enige dagen geduurd heeft voordat de zaken in Nieuw-Amsterdam geregeld waren.

Dadelijk na de aanvaarding van het bewind vaardigde de met het bestuur van Suriname belaste Sir ChARLES Green een proclamatie uit, waarin ten strengste werd verboden personen, behoord hebbende tot de Bataafse troepen in garnizoen, die zich van hun corpsen verwijderd hadden, te huisvesten of te verbergen. Deze personen zelf werden aangemaand zich binnen veertien dagen te melden ,op poene van als Vagebonden te worden beschouwd, als zoodanig opgevat en behandeld te worden".

De berichten omtrent regelingen, getroffen om Suriname, tien jaar later, weer in Nederlands bezit te stellen zijn zeldzaam.

In de Sur. $C r t$ van Vrijdag 7 Jan. 1814 verscheen de volgende aankondiging: „Het is met het uiterste Vergenoegen dat ik aan mijne Leezers de verheugende tijding kan mededeelen, dat Holland dit eertijds zo rijke bloeyende Land, hetwelk door een zamenloop van omstandighedens en ongelukken bijna tot niet was teruggezonken, zig wederom onder de Rang der Natien heeft hersteld".

,Uit de volgende Extracten der Engelsche en Hollandsche Couranten zullen mijne Leezers zich een idee kunnen vormen van den staat der zaken in ons beminde en zo lang onderdrukt geweest zijnde Vaderland". Uit deze uittreksels blijkt van een vergadering van de voornaamste leden en ministers van het oude gouvernement van 1795, ten huize van GIJSBERT KAREL VAN HOGENDORP op de Kneuterdijk gehouden.

In de Sur. Crt van 8 Jan. 1814 wordt met vette letters ,Oranje Boven" gedrukt en de lezers worden geluk gewenst met de omwenteling in Holland.

Op 10 Februari 1814 kondigde Gouverneur Bonham aan, vanwege Zijne Koninklijke Hoogheıd de Prins-Regent van Engeland last te hebben bekomen af te kondigen, dat de aloude betrekkingen van vrede en vriendschap tussen Zijne Majesteit en de Verenigde Nederlandse Provinciën gelukkig weer zijn hersteld. Eerst op 8 Juni verscheen de proclamatie, dat het Zijne Majesteit heeft behaagd, ,uit aanmerking van de grote gebeurtenissen onlangs in Europa voorgevallen om de Commissie van den Ontvanger en den Bestierder der Eigendommen van afwezigen op te schorsen". Aan deze, John Bent geheten, 
werd daarbij last gegeven de eigendommen, welke hij onder zijn bestier mocht hebben weer over te geven.

Wij lezen in de Sur. Crt van 6 Sept. 1814 een bericht uit de Times van Juni 1814, meldende dat op 31 Mei de vrede aan het volk van Parijs is bekend gemaakt. Het vredesverdrag is in dit en de volgende nummers uitvoerig opgenomen.

Omtrent de regelingen, welke door de grote mogendheden voor de bezittingen buiten Europa getroffen zijn, blijven de inwoners van Suriname lang in onzekerheid. In de Sur. Crt van 5 Nov. 1814 , no. 89 , wordt een uittreksel overgenomen van ,,de laatste papieren met de Vloot overgebracht”, waarin wij lezen dat uit Londen op 31 Augustus wordt gemeld, dat Demerary, Essequibo en Berbice aan Engeland zullen blijven en Suriname, Curaçao en St. Eustatius aan Nederland zullen worden teruggegeven. Ten aanzien van Curaçao en St. Eustatius wordt gemeld: „,De waarde van de twee laatste is grotendeels vermindert, doordien thans de Haavens op de Vaste kust van Zuid America open zijn, voor een vrije handel, van welke handel boven gemelde twee eilanden het Canaal en stapelplaats waaren, waarvan alle Europeesche Smokkel Goederen in dit Land ingevoert wierden”. ,De reeden waarom wij Demerary behouden, is zeer bevattelijk vermits hetzelve meest gecultiveert is bij Engelsche Geld, waarvan een groot gedeelte in dat Land terwijl wij het in ons bezit hebben, is ingestoken".

Van het vertrek van gouverneur BoNHAM en de overgave van de kolonie blijkt uit de nieuwsbladen niets. Een advertentie, op 26 Januari 1816 in de plaatselijke bladen opgenomen, nodigt degenen, die vorderingen op de gouverneur hebben, deze binnen zes dagen in te zenden, en in de Sur. Crt van 7 Febr. 1816 lezen wij, dat Bonham met VAN PANHUYs is overeengekomen, dat alle deserteuren zullen worden overgegeven op woord van eer en het publiek gewaarschuwd wordt geen soldaten te verbergen.

De aanvaardingsproclamatie (G.B. I8I6 no. $I$ ) of de aankondiging daarvan vindt men in de pers niet opgenomen.

Het is jammer, dat omtrent de juiste datum van de aankomst van generaal-majoor VAN PANHUYS in Suriname en de overgave niets in de nieuwsbladen is te vinden, omdat hieromtrent een verschil van mening bestaat. EINAAR zegt in een noot op blz. 132 van zijn proefschrift, dat WoLBERS de datum van de aankomst van VAN PANHUYs ten onrechte op 26 Januari stelt, en acht de mededeling in de Encyclopaedie van Nederlandsch West-Indië, blz. 235, dat Suriname op 27 Februari 1816 Nederlands werd, 
niet juist.-Volgens een door hem geciteerde missive van BonHAM is Suriname op 26 Februari aan Nederland teruggegeven 1).

B innenlands nie uws.

Zoals reeds vermeld, is het binnenlandse nieuws schaars; zelfs grote gebeurtenissen worden niet of nauwelijks vermeld. Af en toe worden aan overledenen gedichten gewijd, hoogdravend van stijl. Als voorbeeld hiervan moge vermeld worden een „,grafschrift" voor P. W. SpillenaAR, oud-raad in den Hove van Politie en Criminele Justitie, die op 31 October 1812 in de ouderdom van 67 jaren, 6 maanden en 6 dagen overleed. Het vier coupletten beslaande gedicht eindigt met: Wie was deze brave man? / Vraagt gij O, Wandelaar. / Het was mijn beste vriend, / Zijn Naam was Spillenaar.

Aan de aankomst van gouverneur Bentinck, op 2 Mei 1808, wordt nogal aandacht besteed, en van de parade ter viering van de verjaardag van de Britse Koning, op 7 Juni 1809, wordt een vrij uitvoerige beschrijving gegeven. Wij lezen dat vier compagniën blanke burgers, de burger-mulatten en negercompagniën aan de parade deelnemen, alle voorafgegaan door ,,cierlijk uitgedoschte Bendes Muziekanten". Een groot bal ten Gouvernementshuize besloot dit feest, waarbij het aanwezige gezelschap ,,zig tot het aanbreken van de dag met dansen heeft bezig gehouden".

Bij de dood van Bentinck, op 18 November 1811, verscheen een necrologie, waarin werd vermeld, dat de gouverneur met militaire eerbewijzen en al het respect en eerbied, aan zijn rang en hoge staat verbonden, is ter aarde besteld. In de Sur. Crt van 9 Nov. 1811 is een aankondiging opgenomen waarin de „Lieutenant-Gouverneur” gebiedt (in de Engelse vertaling staat ,,desires"), ,dat een iegelijk gedurende de tijd van 14 dagen betaamlijk in de rouw zal verschijnen".

WOLBERS (blz. 559) vermeldt, dat met BENTINCK medekwam een predikant van de Hervormde Gemeente, ds Pieter JaN

1) In 1941 werd het feit herdacht dat Suriname weder 125 jaar onder Nederlands bestuur was. Omtrent de datum van overgave, 26 of 27 Febr. 1816, werd tussen schrijver en een onbekende inzender, in De West van 26 Febr. 1941, een debat gevoerd. De inzender beroept zich op de proclamatie van VAN PANhuys van 27 Februari, waarin staat ,op heden van deze Kolonie bezit hebben genomen". Merkwaardig is de mening van de inzender, dat de Encycl. Ned. W. I. door zijn politieke en godsdienstige gezindheid niet altijd onpartijdig is. 
van Esch, die vroeger op Curaçao had gestaan 1). Uit de Sur. Crt van 26 Juli 1809 blijkt, dat hij op Zondag 23 Juli zijn intreepredikatie hield en, na een inleiding uit Nehemia 1-11, naar aanleiding van het le deel van vers 16 van het eerste hoofdstuk van de Zendbrief van Paulus aan de Romeinen preekte. De collecte ten bate van de armen bracht 479 gulden op.

Van de plechtige begrafenis van oud-gouverneur FREDERICI, waaraan gouverneur BonHAM deelnam, verscheen in de Sur. $C r t$ van 13 Oct. 1812 een beschrijving. Uit de advertentie van de veiling van de inboedel blijkt dat mathematische instrumenten, fraaie geweren, goud, zilver, kristal en negers werden verkocht.

Ingezonden stukken komen in de door mij geraadpleegde bladen uiterst zelden voor. In de Sur. Crt van 3 Aug. 1808, no. 62 protesteert ene VAN THOL tegen beweringen ten aanzien van de gewezen gouverneur van Demerary, A. Mertens, gedaan in een boek van de hand van zekere BolingBRoke 2). Hij zegt, dat ieder die in de zusterkolonie bekend is, ,,de valsiteit daarvan zal blijken, tenzij de auteur de pen geleend heeft van heer Huybert wiens grootste vermaak het was om loogens te spreken of te schrijven". In het volgende nummer van de krant komt BolingBRoKe tegen deze critiek op en schrijft, dat het , klaarlijk en uitdrukkelijk mag verstaan worden dat ik nooit mijne Reflectiën zal terugtrekken ten opzigte van de publicque Ambts betrekking van den heer Mertens geduurende de tijd dat dezelve als Gouverneur van die Colonie was fungeerende, zo bijaldien hij zich beledigd vind, zijn de Engelsche Gerechtshoven die door de geheele waereld beschouwd worden en erkent als de hoogste toppunt van gerechtigheid open om Recht te verleenen aan die geenen die met een zuiver geweeten te werk gaan".

Over het werk van BoLINGBRoke is een bespreking overgenomen uit de Essequibo en Demerary Courant van 3 Sept. 1808: ,De auteur is zo min een man van talenten als van de waarheid in historieschrijven; dit boek heeft slechts eene goede hoedanig-

1) Over ds. Van Esch raadplege men De GaAy Fortman in $W . I$. Gids 26,1945 , p. 234 , en 25, 1943, p. 255 en EINAAR, diss., 1934, p. 80, 90 en 122. Hij stierf te Paramaribo op 2 Dec. 1814 in de ouderdom van 50 jaar en 5 maanden.

2) Menkman deelt mede, W. I. Gids 17, 1936, p. 331, dat Henry BolingBroke zes jaar in Suriname is geweest en een reisbeschrijving uitgaf: A voyage to the Demerary. 
heid en eene zodanige waarmede Bolingbroke niets te doen heeft, namelijk dat hetzelve op dik, hard, glad papier wel gedrukt is". Zó medogenloos was de critiek in 1808!

Wie was deze BolingBroke? EINAAR (blz. 66) vermeldt, dat HenRY BolingBroke in 1807 tot vendumeester in Suriname werd benoemd. Uit een onderzoek bleek dat hij een salaris van $f 10.000$ genoot. In Wolbers lezen wij, dat BOLINGBROKE door het Britse Gouvernement naar Suriname was gezonden om dit ambt te aanvaarden, en dat de toenmalige functionaris, CAMEkon, hem dit officie niet wilde overgeven. In de Surinaamse kranten worden herhaaldelijk veilingen, door BoLINGBROKE gehouden, aangekondigd. Ondanks zijn hoog salaris en zijn grote eerbied voor de Engelse justitie blijkt deze Engelse vendumeester niet the right man in the right place te zijn geweest. In de Sur. Crt van 28 Aug. 1812 staat een oproep van de Eerste Raad-Fiscaal E. G. VELDWIJK, daartoe geautoriseerd door de Edelachtbare Hove van Politie en Criminele Justitie ,omme terzake van het bevonden deficit van Penningen in de Kas van de Gedeputeerden Vendumeester Henry Bolingbroke jegens hem te ageren tot maintien van het recht van de Hoge Overigheid". BolingBroke, aan wie huisarrest was opgelegd, bleek in de avond van 25 Augustus te zijn gevlucht, en een premie van $f 1000$ werd uitgeloofd voor degenen, die hem in handen van de Justitie overleverden. Merkwaardig is het signalement: ,35 jaar oud, middelmatig van postuur, rond van wezen, eenigszins trippelende gang en stotterend van spraak". Of het gelukt is hem te vangen blijkt niet uit de Surinaamse pers.

Als bewijs van de juistheid van de mening van WolBERS, dat de Britse autoriteiten met gematigdheid te werk gingen en de inwoners door toegeeflijkheid trachtten te winnen, vermelden wij een brief, waarin John Martyr, A. W. White, J. J. FreDERICI en W. LECKIE aan luit.-kol. Sir JOHN WARDLAW schreven, waarin diep leedwezen werd uitgesproken over het vertrek van het 64e regiment uit Suriname, omdat men daardoor werd beroofd van het gezelschap van officieren, met welke de ingezetenen gedurende de tijd van omtrent negen jaren, op de openhartigste en vriendelijkste voet verkeerd hadden. In een vriendelijk schrijven bracht WARDLAw dank namens zijn officieren. Beide brieven zijn overgenomen uit de Barbados Mercury in de Sur. Crt van 15 Mrt 1813.

De erkentelijkheid voor het optreden der Engelsen bracht evenwel niet mede dat Holland vergeten werd. Een intekenlijst 
voor bijdragen tot leniging van de nood, door de ramp van Leiden veroorzaakt, bracht $f 14.144$ op.

Ten slotte: De notificatie van 12 September 1809, dat gedurende de droge tijd op de gouvernements-secretarie van 7 tot 11 uur gewerkt werd, zal door de tegenwoordige ambtenaren, die tot 13.30 uur moeten doorwerken met enige afgunst worden gelezen.

Buitenlandse berichtgeving.

Uit de buitenlandse bladen werden berichten omtrent de politieke toestand in Europa overgenomen; natuurlijk meestal ontleend aan bladen uit Engeland, Barbados of Brits-Guyana. Slechts een enkele maal blijkt van de ontvangst van Nederlandse couranten.

Over Nelson en Wellington, en hun krijgsverrichtingen, worden de lezers ingelicht.

Merkwaardig is het verschil in berichtgeving omtrent NAPOLEON. In Maart 1804 verschijnt een artikel over het karakter van de eerste Consul van Frankrijk. Wij lezen daarin, dat hij een Corsikaan van geboorte is, niet groot doch welgemaakt, fraai van tanden en handen, donkere ogen, in de neus enigszins naar de Romeinen trekkend. Van hem wordt gezegd dat hij altoos zeer behoedzaam was om mensenbloed te plengen en zijn gewonden zowel als gevangenen met de uiterste menselijkheid behandelde. - Na de inbezitneming van Suriname door de Engelsen wordt het oordeel van de Surinaamse pers over de man, die Europa beheerste, enigszins anders. In de krant van 22 Febr. 1806 staat: ,Jan vroeg aan Nicolaas, / Waarom Gelijkt Bonaparte na een Trom? / Dat zal ik je zeggen, antwoordde Klaas. / Hoe meer m'hem klopt, hoe meer geraas".

De Sur. Crt van 4 Juni 1806 neemt een lijst op van koningen en prinsen, door BONAPARTE aangesteld of nog aan te stellen, en uit het Engelse blad Globe van 24 Sept. 1808 wordt het volgende overgenomen. ,Y Yder dag welke voorbij gaat en met ydere nieuwe informatie die wij van het vaste land ontvangen worden wij, hoezeer dezelven ook om de oogmerken van den nog heerschende en Europa onderdrukkende Tyran, te begunstigen, mogen worden verdraayd en veranderd, egter ten klaarsten overtuygd, dat hij reeds van die vreeselijke hoogte waarop hij voor nog slechts eenige maanden stond gevallen is".

In de berichtgeving wordt het Moederland niet vergeten. In 1811 wordt uit de Londense kranten een verslag overgenomen 
van een heer die Holland bezocht heeft en vertelt van de rampspoedige staat, waarin het land door decreten van BoNAPARTE is gekomen, de strenge visitatie der douaniers veroordeelt en verhaalt dat er honger en gebrek wordt geleden.

De doop van de zoon van NAPOLEON geeft aanleiding tot het overnemen uit Engelse bladen van Juni 1811 van verschillende „,Vragen”, waaronder: ,Is het mogelijk dat dit kind tegelijkertijd door den geest van het Christendom en den geest van Bonaparte kan bezield wezen?"

In November 1813 wordt aan de lezers voorgezet: ,De situatie van de Keizerin van Frankrijk in verband met de oorlog van Frankrijk met Oostenrijk is beklagenswaardig. Ter eener zijde moet zij de uitwerkingen van het oploopende en woedende temprament van haar tirranischen Heer vreezen en aan de andere zijde de verschrikkelijke buitensporigheden van Volkswraak".

Een extra editie van de Sur. Crt van 21 Jan. 1808 meldt de capitulatie van Cayenne, en in Maart, bij de overwinning van Martinique lezen wij: ,Dit is de tweede vlucht van dit Napoleons voddegoed" (,,boubles" in het Engelse deel van de krant).

De berichten van het mislukken van de veldtocht naar Rusland en de verbanning naar Elba worden, uiteraard maanden later, met vreugde aan de lezers medegedeeld. - Het duurt tot 4 Mei 1815, voor de inwoners van Suriname kennis krijgen van de landing op 1 Maart in Frankrijk, en eind Mei bericht de redactie, dat Bordeaux in de macht van de geweldenaar is. Het bulletin van Downingstreet over de nederlaag bij Waterloo en de proclamatie tot het Franse volk van Wellington komt in Augustus i 815 ter kennis van het Surinaamse publiek, dat eerst op 23 November 1815 verneemt, dat de ex-keizer naar St. Helena is verbannen.

Advertenties.

Behalve officiële aankondigingen van benoeming van ambtenaren, aanvragen om manumissiebrieven, aankondigingen van vertrek uit Suriname en gouvernementele kennisgevingen, lezen wij uit de advertenties wat de kooplieden aanbieden, en welke huizen en plantages ten verkoop worden aangeboden. Vaak wordt melding gemaakt van slaven die ,,geabsenteerd" zijn en vanggeld aangeboden. Met veel omhaal worden doodsberichten opgenomen, de jaren, maanden en dagen die de overledenen bereikten, gemeld en hun goede hoedanigheden opgesomd.

Reeds in November 1806 plaatste de assurantiemaatschappij „Phoenix” advertenties. 
Merkwaardig is dat zekere C. F. F. Fishers in December 1806 zich bereid verklaart de plantage-eigenaren te leren ,hoe de slaven tot werken zijn te animeren zonder hun te straffen en tevens punch voor hen te maken, omdat zij in dit seizoen niet verkouwt raken".

In die jaren werd veel aan toneelspel gedaan. „De Verreezene Phoenix”, 't Genootschap „Door Yver bloeit de Kunst” en „Oefening kweekt Kunst" geven vaak acht tot tien voorstellingen per jaar. Meestal wordt een drama en een blijspel opgevoerd. Veel stukken van P. A. van KotZebue, o.a. het ook vele jaren later nog met veel succes opgevoerde toneelstuk „De Spanjaarden in Peru of de dood van Rolla", worden ten tonele gebracht. Enigszins ironisch klinkt het, dat op 17 April 1806 wordt opgevoerd: „Vrijheid, Gelijkheid en Broederschap”, aangekondigd als Vaderlandsch Kluchtspel. Op 11 Februari 1811 werd door De Verreezene Phoenix „De zege der oude liefde”, toneelspel door Abraham Vereul, opgevoerd 1).

Af en toe werden door particulieren voorstellingen gegeven. Machiel Salomons, die zich dansmeester noemde, gaf op 27 November 1806 een ballet, waarin volgens zijn aankondiging nieuwe solo's zouden worden gedanst. Met deze voorstelling ging het niet zo vlot, want in de Sur. Crt verscheen een advertentie van SALOMons, waarin hij het geachte publiek mededeelde „dat het lossen van het geschut der twee schepen verhinderd was geworden door kwaadzuchtige lieden, welke de ingrediënten hadden nat gemaakt". De prijzen waren waarlijk niet laag; voor loge werd $f 10$, voor de bak (pitt) $f 5$ gerekend.

Niettegenstaande deze hoge prijzen konden niet alle toneelverenigingen in stand blijven. C. ROEPEL, eerste exploiteur, kondigde aan dat hij op Vrijdag 28 Juni 1811 ter Castelenye van den Hove Civiel publiek zou verkopen ,'t Toneelgebouw staande op de hoek Keyzer en Klipsteenenstraat, aankomende het genootschap Oefening kweekt Kunst".

WOLBERS (blz. 563) vermeldt als bewijs van de vrij algemene goede gezindheid der Engelsen jegens de Surinaamse burgers, dat de Engelse officieren toneelstukken opvoerden in het gebouw van het toneelgezelschap der Joden, De Verreezene Phoenix, en de opbrengst gebruikten om personen, die voor schulden in de gevangenis zaten, uit hun kerkers te verlossen. Dit doel werd bij de aankondiging der stukken bepaaldelijk uitgedrukt.

1) Abraham Vereul, dichter en schrijver van toneelstukken; zie W. I. Encycl. p. 707 en W. I. Gids 8, 1927, p. 378. 
In de nieuwsbladen welke door mij werden geraadpleegd waren dergelijke aankondigingen niet te vinden. Wel werd in de Sur. Crt van 31 Mei 1806 geadverteerd, dat door een liefhebberijtoneel drie achtereenvolgende representatievoorstellingen zouden worden gegeven voor het benefit van de ongelukkige families van de Engelse matrozen die in de victorieuze slag bij Trafalgar roemrijk waren gesneuveld; en voor 17 Augustus 1815 werd een voorstelling aangekondigd voor het fonds tot aanmoediging van de gewapende dienst in de Nederlanden.

\section{S U M M A R Y}

THE PRESS IN SURINAME IN 1804-1816, THE PERIOD DURING WHICH THE COLONY WAS UNDER BRITISH SOVEREIGNTY

The author states that the above mentioned historical period has already inspired several writers, such as Wolbers, EInaAr, MENKMAN and Oudschans Dentz, whereas de GaAy Fortman published a history of Curaçao under British rule (1807-1816).

In the present article the following subjects come to the front, i.e.

1. The Press. The newspapers (the names are given of ten printing shops) appeared in both the English and the Dutch languages. The importation of foreign papers was subjected to the approval of the governor. The editors at Paramaribo published nothing but official notices, advertisements and foreign news, the latter derived from the newspapers of Demerary, Barbados, the United States, sometimes from European sources.

2. Con quest of Surin a m e. The Surinaamsche Courant on May 5th 1804 was still unaware of the loss of the Colony to Great Britain, although an English maritime force had already taken the fortifications down the Suriname river on one of the last days of April. The same newspaper published on May 30th the proclamation of Sir CHARLES GreEN, the first English governor, dated May 19th, stating that Suriname had become a British crowncolony and that the inhabitants had to swear an oath of allegiance to His Majesty.

3. Restitution of Suriname to Holland. On Jan. 7th and 8th 1814 the Sur. Crt. informed its readers of the revolution in Holland and on Febr. 10th of the same year governor BonHAM announced that the former relations of peace and friendship between Great Britain and the Dutch Republic were happily restored. Not before June 8th 1814 the commission of JoHN BENT as receiver and trustee of the properties of absentees was suspended and BENT was ordered to surrender all properties still in his custody.

In the Sur. Crt. of Sept. 6th 1814 we find a notice taken from the Times of about three months earlier, saying that on May 30th peace was made known to the population of Paris. The peace treaty was published in full in this and following issues. What the allied powers had decided about the colonies remained uncertain for a long time. From the 
Sur. Crt of Nov. 5th 1814 could be learned that Berbice, Demerary and Essequibo were likely to remain Britsh, Curaçao and Saint Eustatius to be returned to Holland.

An advertisement of 26th January 1816 in the local newspapers summoned creditors of the parting governor BonHam and the Sur. Crt of Febr. 7th 1816 speaks about an agreement between him and VAN PANHUYS with regard to deserted soldiers. For the rest the newspapers are silent about the departure of the last English governor and the transfer of the colony. The proclamation by which van PANHUYs took office is only to be found in the Gouvernements Blad I8I6 no $I$.

About the exact date of the arrival of the new Dutch governor and of the transfer of government, historians are not unanimous and therefore it is to be deplored that the local newspapers do not give exact information.

4. L o c a l n e w s, as has already been stated, was scarce.

Sometimes prominent inhabitants who had died were commemorated in gradiloquent verse.

Pretty much notice was taken of the arrival of governor BENTINCK on May 2nd 1808, of the celebration of H.B.M's birthday on June 7th 1809 and of the military parade and the ball at government house on that occasion. On Bentinck's death, Nov. 18th 1811, a necrology of the deceased governor appeared, as well as an account of the burial. In the Sur. Crt. of Nov. 19th the lieutenant governor ,,desired" that everybody should adopt a decent mourning for a period of 14 days.

In the number of July 26th 1809 of the same paper the first sermon is mentioned preached by Ds PIETER JAN VAN Esch, arrived together with BENTINCK, as also the proceeds of the collection, held among the congregation on behalf of the poor.

Of the ceremonious obsequies of the late governor FREDERICI, which governor BonHam attended, the Sur. Crt of Oct. 13th 1812 contains an account, whereas an advertisement of the public sale of the defunct's household goods gives details about his belongings, negroes included.

Letters to the editors the author of this article has seldom found in the papers consulted by him. One worth mentioning appeared in the Sur. Crt of Aug. 3rd 1808, by which a protest was uttered against certain assertions at the expense of A. MERTENS, former governor of Demerary, contained in the book written bij Henry BolingBroke. The author of the present article gives some information about the said BoLINGBRoKe.

The Sur. Crt of March 15th 1813 copies two letters which had appeared in the Barbados Mercury, one signed by three gentlemen of Paramaribo, adressed to Sir JoHn WARDLAw, expressing regret about the departure of the 64th regiment from Suriname, the other of WARDLAw, thanking the writers in the name of his officers. The British authorities apparently had done everything in their power to befriend the inhabitants of the Colony. That these last on the other hand did not forget the mothercountry appears from the fact that more than 14.000 guilders were contributed for the relief of the people who had suffered by the calamity of Leiden.

5. F o r e i g n n e w s was mostly taken from papers issued in England and British Guiana, or at Barbadoes. Dutch papers apparently were received very seldom. Readers were informed about NELSON and 
WELLINGTON and about their military operations. Very remarkable is the abrupt change in the communications about NAPOLEON. In 1804 he is still the loyal and humane first Consul, in 1806 he is a hollow braggart, in 1808 a tyran and so on until Waterloo. An extra edition of the Sur. Crt of Jan. 21st 1808 announces the capitulation of Cayenne. NAPOLEON's defeat of the 18th of June and WELLINGTON's proclamation to the French people come to the knowledge of the public in Suriname on August 1815, the banishment of the ex-emperor to Saint-Helena on the 23rd of November.

6. A d vertis e ments. Commercial advertisements referred to goods offered by the local merchants, houses and plantations for sale. Often runaway slaves are advertised and rewards for seizure promised. Obituary notices give the ages of the deceased in years, months and days and sum up their good qualities. In Nov. 1806 already the insurance company ,"Phoenix" advertises.

Remarkable is the offer of a certain Fishers in Dec. 1806, to instruct planters in the art of animating slaves to work, without chastising them and at the same time to make punch for them, to prevent their catching cold in this season.

Several theatrical societies announced performances in the newspapers; a dancing master produced a ballet on Nov. 27ht 1806. According to WoLBERs the officers of the British garrison produced plays in the Jewish theatre, for the benefit of insolvent debtors, suffering in prison. The author of the present article did not find any announcement to this effect. What he did find, Sur. Crt May 31 1806, was one of a society of amateurs which intended to give three performances for the benefit of the unhappy families of British sailors, killed in the battle of Trafalgar. For August 17th 1815 a performance was announced on behalf of the fund for the encouragement of military service in Holland. 